\title{
EVALUATION RESULTS OF THE USE OF MODERN INTERNET SOURCES BY THE STUDENTS OF VOCATIONAL EDUCATION INSTITUTIONS FOR THE FORMATION OF HEALTH AWARENESS
}

DOI: 10.36740/WLek202105102

\author{
Valeriya V. Brych, Habriella V. Dudash, Viktoria Y. Bilak-Lukyanchuk, Mariana M. Dub, Ivanna Y. Hutsol \\ UZHHOROD NATIONAL UNIVERSITY, UZHHOROD, UKRAINE
}

\begin{abstract}
The aim: Is to evaluate students' use of online tools to obtain information on health and healthy lifestyle.

Materials and methods: A sociological survey was conducted among 1,563 students of vocational education institutions in Transcarpathian region, using a specially designed questionnaire on the use of information and communication channels to inform about health and healthy lifestyle.

Results: It was found that a large proportion of students of vocational education institutions $(71.8 \pm 2.2 \%)$ spend more than 2 hours a day browsing Internet resources, which makes it possible to use these information and communication channels to inform about health and healthy lifestyle. The most relevant sources of information about health for young people are social networks Facebook $(58.3 \pm 2.4 \%)$ and Instagram $(56.7 \pm 2.5 \%)$, webpages of famous doctors $(34.9 \pm 2.4 \%)$ and official websites of health care institutions (32.4 $2.3 \%)$.

Conclusions: Effective use of modern information and communication channels for health promotion among students aged 15-18 is possible taking into account the preferences of the target group, their features, reliable information content.
\end{abstract}

KEY WORDS: Internet, health, healthy lifestyle, students, information and communication channels

Wiad Lek. 2021;74(5):1061-1064

\section{INTRODUCTION}

The expansion of information and communication technologies in our society has led to many positive elements, including new means of communication, work, study and entertainment, in space and time. Browsing the Internet, using social networks, video games and mobile phones have led to a drastic change in lifestyle, especially among young people, also known as digital users, who actively use these devices [1].

Since the appearance of the Internet, society has become integrated into world culture, which has influenced both health care and education [2]. Vocational education in accordance with the Law of Ukraine "On Vocational (Technical) Education" is a component of the education system of Ukraine, a set of pedagogical and organizational and managerial measures aimed at ensuring the acquisition of knowledge, skills and abilities in chosen field of professional activity, development of competence and professionalism, upbringing general and professional culture. Young people aged 15-20 study in vocational schools. But the main part are teenagers aged 15-18. It is at this age that you can develop a culture of health and a healthy lifestyle.

Adolescents spend more and more time with their smartphones, visiting social networks, mainly Facebook, Instagram and Twitter, etc. [3]. Social networks take over the lives of teenagers and change their attitudes towards others. They create their own changing culture [4].
According to research, $75 \%$ of adolescents use a smartphone during school time, and $98 \%$ use it at midnight. Many teenagers sleep with their smartphones under pillows (45\%) and check their devices at night (60\%). Moreover, $57 \%$ of them use a smartphone within ten minutes after waking up, and $80 \%$ fall asleep holding a smartphone [3].

Adolescence is a critical time to establish the foundations of human health and can be crucial for further health and disease development, as it is known that habits acquired during this period can be traced in adulthood [5].

Given the myriad of media channels and available health information, it is important to explore how health consumers navigate and choose from numerous media channels in search of health information and preferences among different sources of information [6].

Researching teenagers' healthy habits, interest in health and healthy lifestyle pages on the Internet, social networks, the media and the impact of such pages on the level of knowledge and responsible attitude to one's health can be important for health care policy, in particular, developing programs and implementing interventions aimed at promoting health and healthy lifestyle among young people.

\section{THE AIM}

The aim is to evaluate students' use of online tools to obtain information on health and healthy lifestyle. 


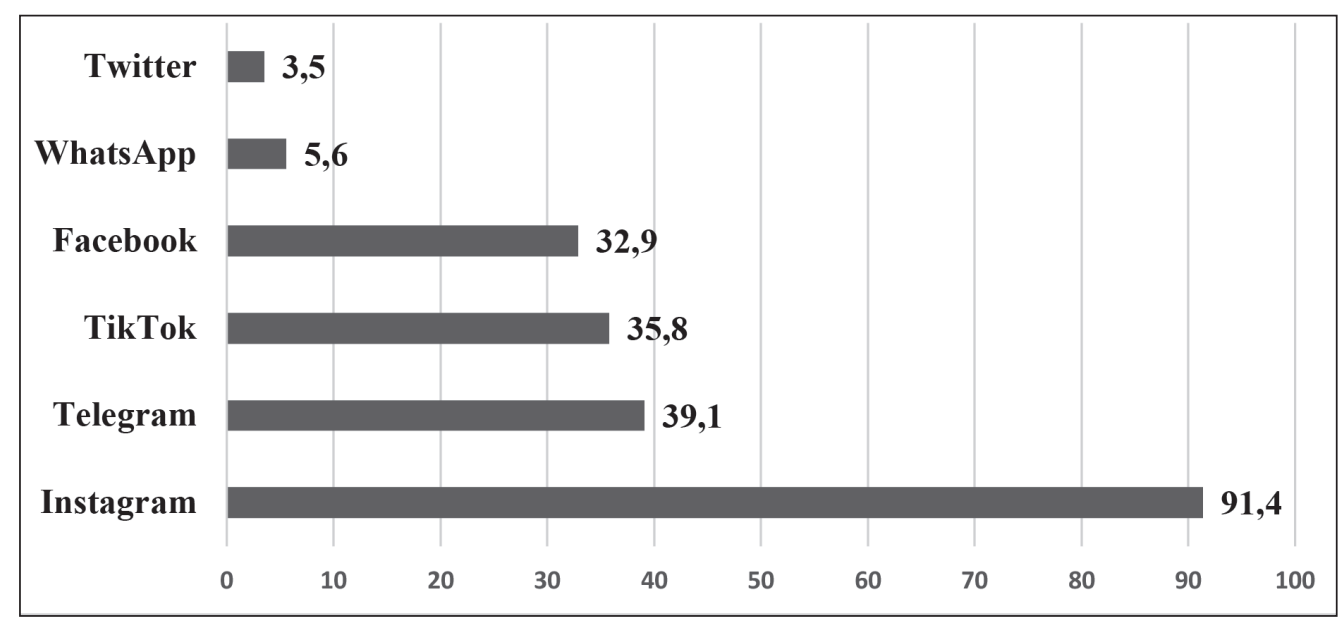

Fig. 1. Priority of respondents' use of social networks (\%)

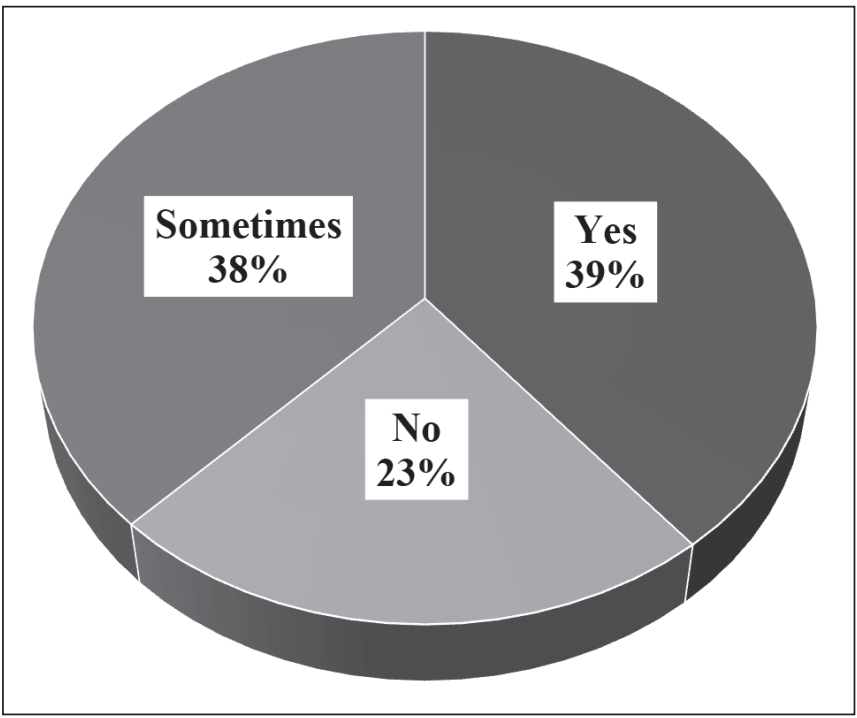

Fig. 2. Distribution of respondents' answers to the question "Are you attracted to images of healthy food and people engaged in physical activity in the news feed of social Internet sources?"

\section{MATERIALS AND METHODS}

Medical-statistical, sociological, graphic and bibliosemantic methods were used during the research.

1563 students of vocational education institutions of Transcarpathian region were involved in the sociological research. Distribution of respondents by age: $15-16$ years - 56.0\% (874 persons), 17-18 years - 42.0\% (657 persons), $19-20$ years - $1 \%$ (16 persons), $21-22$ years $-1 \%$ ( 16 people); by gender: female $-39.5 \%$ (618 people), male $-60.5 \%$ (945 people). A specially designed questionnaire included general data and questions on the use of information and communication channels to inform about health and healthy lifestyle.

Percentages of answers with a confidence interval of 95\% were determined. The licensed program IBM SPSS Statistics and Microsoft Excel were used to calculate the obtained data.

The application of these methods in the study was reviewed and approved by the Committee on Ethics of State Higher Educational Institution «Uzhhorod National University» (Protocol No. 3 of May 19, 2020).

\section{RESULTS}

The analysis of the respondents' answers allowed to determine the time of their daily use of Internet means. It was found that the largest share of surveyed students $(38.5 \pm 2.4 \%)$ are on the Internet for more than 4 hours daily, $33.3 \pm 2.3 \%$ - for $2-4$ hours, $22.7 \pm 2.1 \%$ - $1-2$ hours and only $5.5 \pm 1.1 \%$ of people confessed that they spend less than 1 hour on the Internet.

The next task was to determine the priority of viewing social networks $-91.4 \pm 1.4 \%$ of students said that they prefer Instagram. Almost 2.5 times less they use other networks: Telegram $-39.1 \pm 2.4 \%$ of respondents, TikTok $-35.8 \pm 2.4 \%$, Facebook $-32.9 \pm 2.3 \%$ (Fig. 1).

To achieve our goal, we needed to determine the extent to which online resources were being used to raise awareness about health and healthy lifestyle. Almost half of the research participants $(47.7 \pm 2.5 \%)$ noted that they rarely visit websites about a healthy lifestyle, and $17.5 \pm 1.9 \%$ do this never at all. It was determined that $24.9 \pm 2.1 \%$ of surveyed students not only frequently visit such pages, but also follow the advice given there.

At the same time, it was found that only $14.9 \pm 1.8 \%$ of surveyed students indicated that they often use advice or information on maintaining health from websites and social networks. The analysis of answers showed that $52.2 \pm 2.5 \%$ of respondents sometimes use this information, $33.1 \pm 2.3 \%$ do not use it at all. At the same time, only $12.9 \pm 1.7 \%$ of young people believe that such information is reliable, and $52.7 \pm 2.5 \%$ said that sometimes such information can be trusted.

It was determined that only $23.3 \pm 2.1 \%$ of surveyed students said that they were not attracted to the news feed of Internet sources depicting healthy food and people engaged in physical activity (Fig. 2).

Sources of health information that are appropriate for the coverage of health information according to the research participants were also identified. The largest number of surveyed students $(36.1 \pm 2.4 \%)$ want to receive information about health and healthy lifestyle from social networks, a slightly smaller number - from the webpages of famous doctors $(34.9 \pm 2.4 \%)$ and official websites of health care institutions (32.4 $\pm 2.3 \%$ ). $30.5 \pm 2.3 \%$ of young people pre- 

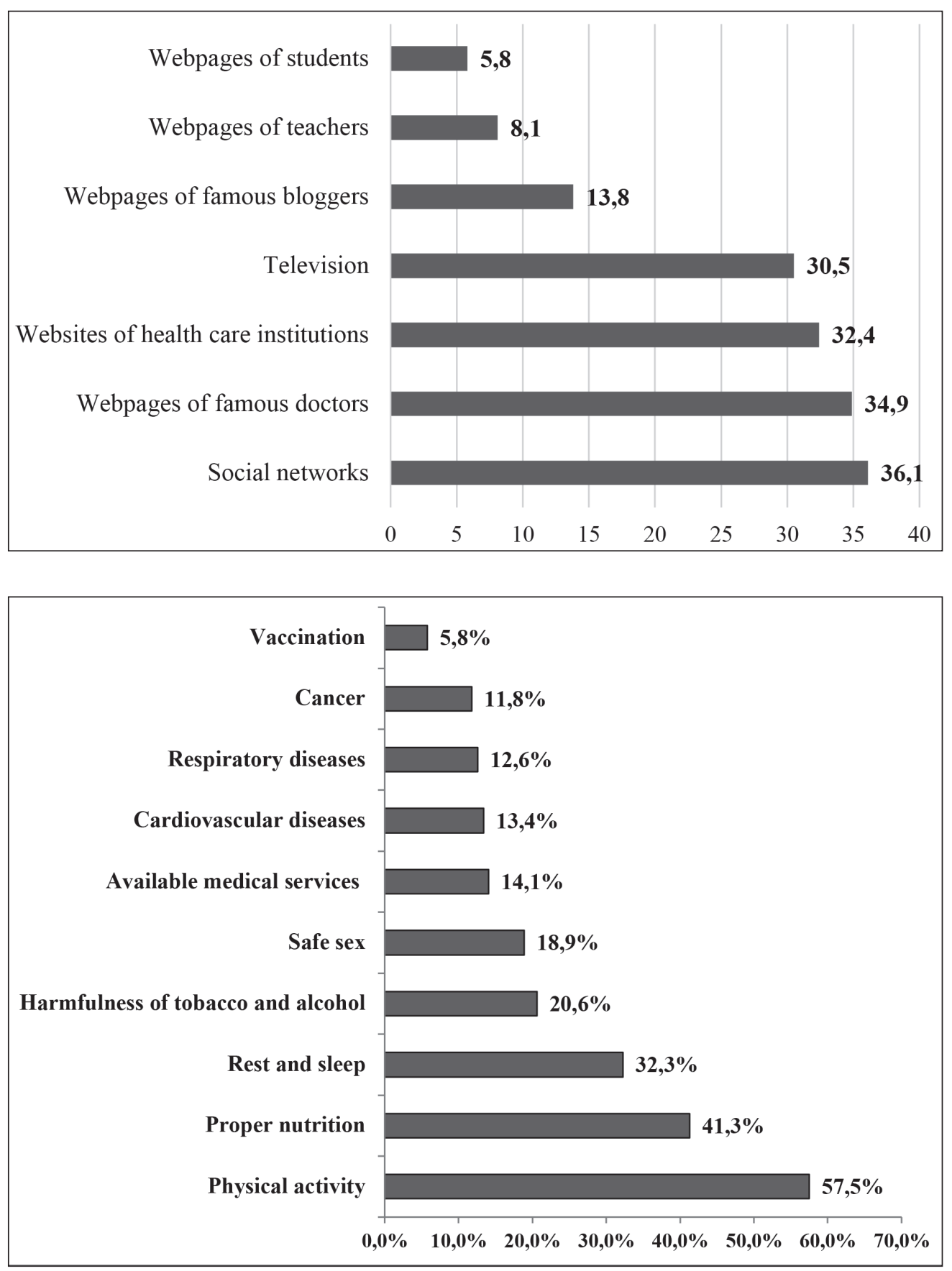

Fig. 3. Distribution of answers on the desired sources of information about health and healthy lifestyle (\%)
Fig. 4. Health topics desirable for the respondents ferred television. Other sources were mentioned by more than 2 times fewer students (Fig. 3).

As the largest number of participants indicated social networks as the preferred source of health information, the question of determining the social network that is best suited for this became relevant. Thus, $58.3 \pm 2.4 \%$ of students mentioned Facebook, 56.7 $\pm 2.5 \%$ - Instagram, and $27.1 \pm 2.2 \%$ - Telegram.

Students were asked to choose health topics interesting for them. It was revealed that the most interesting for them are information materials about popular components of healthy lifestyle: physical activity $(57.5 \pm 2.5 \%)$, proper nutrition $(41.0 \pm 2,4 \%)$, proper rest and sleep $(32.3 \pm 2.3 \%)$. They are less interested in the harmfulness of tobacco and alcohol (20.6 $\pm 2.0 \%)$, safe sex $(18.9 \pm 1.9 \%)$, available services in medical institutions at the place of their residence $(14.1 \pm 1.7 \%)$, diseases of the cardiovascular system $(13.4 \pm 1.7 \%)$, respiratory diseases $(12.6 \pm 1.6 \%)$, cancer (11.8 $\pm 1.6 \%)$, vaccination $(5,8 \pm 1.2 \%)$ (Fig. 4$)$.

It should be noted that the results of the survey show that $40.8 \pm 2.4 \%$ of surveyed students are interested in the opportunity to consult anonymously on various health topics on the Internet websites, and $31.0 \pm 2.3 \%$ are undecided.

\section{DISCUSSION}

The World Wide Web is an important part of everyone's life. Because a large proportion of vocational education institutions students $(71.8 \pm 2.2 \%)$ are found to spend more than 2 hours daily, this makes it possible to use these information and 
communication channels to inform about health and healthy lifestyle. Despite the fact that the main social network used by the participants of the survey is Instagram (91.4 $\pm 1.4 \%)$, only $56.7 \pm 2.5 \%$ of respondents see it as a source of health information. They consider Facebook to be the most relevant source of health information (58.3 $\pm 2.4 \%$ ), although only $32.9 \pm 2.3 \%$ of students reported using it. Such differences may be related to the use and content of these social networks - young people more often perceive Facebook as an adult network that contains serious information on various topics, and Instagram as an entertainment platform with a predominance of visual information and minimal verbal content.

Of particular note are the results of the survey, which indicate that a third of students want to get information about health and healthy lifestyle from the webpages of well-known doctors and the official websites of health care institutions. This indicates the need to involve these tools to raise awareness among young people on this topic, which will increase the relevance of all topics related to health.

The study revealed that the most part of surveyed young people were interested in the topics of "physical activity" $(57.5 \pm 2.5 \%)$ and "proper nutrition" (41.3 $\pm 2.4 \%)$. But they are more than 2 times less interested in such important topics as "harmfulness of tobacco and alcohol" $(20.6 \pm 2.0 \%)$ and "safe sex" $(18.9 \pm 1.9 \%)$, which are especially determine the future health of the younger generation. The obtained results reveal the need to update these topics among students of vocational education institutions using modern information and communication channels.

Another possible channel for disseminating information about health and healthy lifestyle is a website with the possibility of anonymous counselling of young people on important topics. $40.8 \pm 2.4 \%$ of surveyed students showed interest in such a website. Well-known highly qualified doctors of various specialties can be involved in the implementation of counselling in this way. At the same time, the site can simultaneously disseminate relevant information necessary for the formation of reliable information about health and a healthy lifestyle.

\section{CONCLUSIONS}

The study allows us to draw the following conclusions:

1. Student youth of vocational education institutions is characterized by a high level of use of the Internet in general and insufficient level of its use to get informed about health and healthy lifestyle.

2. There were determined desired information and communication channels for students about health and healthy lifestyle: social networks (Facebook, Instagram, Telegram), webpages of famous doctors and health care institutions.

3. The structure of topics of interest to students of information and communication channels about health is represented mainly by the topics "physical activity", "nutrition", "rest and sleep" and needs to be corrected in order to update other important topics about healthy lifestyle.

Effective use of modern information and communication channels for health promotion among students aged 15-18 is possible taking into account the preferences of the target group, their features, reliable information content. The results of the research will allow more effective development and implementation of health promotion measures among student youth.

\section{REFERENCES}

1. Muñoz-Miralles R., Ortega-González R., López-Morón M.R. et al. The problematic use of Information and Communication Technologies (ICT) in adolescents by the cross sectional JOITIC study. BMC Pediatr. 2016;16(1):140. doi:10.1186/s12887-016-0674-y.

2. Lopez-Fernandez 0 . Emerging Health and Education Issues Related to Internet Technologies and Addictive Problems. Int J Environ Res Public Health. 2021;18(1):321. doi:10.3390/ijerph18010321.

3. Bozzola E., Spina G., Ruggiero M. et al. Media use during adolescence: the recommendations of the Italian Pediatric Society. Ital J Pediatr. 2019;45(1):149. doi:10.1186/s13052-019-0725-8.

4. Jassogne C., Zdanowicz N. Real or Virtual Relationships: Does It Matter to Teens? Psychiatr Danub. 2020; 32 (1):172-175.

5. Marques A., Loureiro N., Avelar-Rosa B. et al. Adolescents' healthy lifestyle. J Pediatr (Rio J). 2020;96(2):217-224. doi: 10.1016/j. jped.2018.09.002.

6. Zhang L., Qin Y., Li P. Media Complementarity and Health Information Acquisition: A Cross-sectional Analysis of the 2017 HINTS-China Survey. J Health Commun. 2020;25(4):291-300. doi: 10.1080/10810730.2020. 1746868 .

The work was performed within the framework of the Scientific Research Work of the Department of Health Sciences of Uzhhorod National University "Medical and demographic and sanitary and epidemiological situation in Transcarpathian region as the factor of formation of regional public health system".

\section{ORCID and contributionship:}

Valeriya V. Brych: 0000-0003-3741-6002 A, C, D, F

Habriella V. Dudash: 0000-0001-5801-5588 A, B,C

Viktoria Y. Bilak-Lukyanchuk: 0000-0003-3020-316X D,E

Mariana M. Dub: 0000-0002-2737-960X ${ }^{B, D, E}$

Ivanna Y. Hutsol: 0000-0001-7263-8319 ${ }^{B, D}$

\section{Conflicts of Interest:}

The Authors declare no conflict of interest.

\section{CORRESPONDING AUTHOR Valeriya V. Brych \\ Uzhhorod National University \\ 29 Mytna st., 88000 Uzhhorod, Ukraine \\ tel.: + 380505133562 \\ e-mail:valeria.bruch@uzhnu.edu.ua}

Received: 01.12 .2020

Accepted: 30.03 .2021

A - Work concept and design, B - Data collection and analysis, C - Responsibility for statistical analysis,

D-Writing the article, $\mathbf{E}$-Critical review, $\mathbf{F}$ - Final approval of the article 